Identidade e Nação: o sertão nordestino como retórica social e romanesca.

Revista Ensaios, vol. 13, jul-dez de 2018. ISSN 2175-0564.

\title{
Identidade e Nação: o sertão nordestino como retórica social e romanesca
}

\author{
Érika Catarina de Melo Alves ${ }^{1}$ \\ Marcos Diallyson Farias da Silva ${ }^{2}$
}

Resumo: Este artigo tem como base analítica as obras Os Sertões, de Euclides da Cunha, e O Romance da Pedra do Reino e o Príncipe do Sangue do Vai-e-volta, de Ariano Suassuna. O desenvolvimento desta reflexão demonstra como o realismo do primeiro influencia o imaginário bastante singular do segundo. Para tanto, algumas questões se apresentam como temas imperativos para compreensão destas duas obras, no que elas têm de aproximação e distanciamento, como a noção de identidade e nação. Ao realizar um exercício analítico sobre este espaço geográfico na literatura nacional, é possível delinear perspectivas sociológicas deconstituição de lugares como os sertões que por sua vez, evocam imagens, textos e debates e diferenciadas formas de expressão de identidades e a própria noção de nação.

Palavras-chaves: Sertões; Identidades; Nação.

\section{Identity and Nation: the northeastern as social and Romanesque rhetoric}

\begin{abstract}
This article has as an analytical basis the works Os Sertões, by Euclides da Cunha, and The Romance of the Stone of the Kingdom and the Prince of the Blood of the Back, by Ariano Suassuna. The development of this reflection demonstrates show the realism of the first influences the rather singular imaginary of the second. For this, some questions are presented as imperative themes for understanding the set wo works, in which they have of approximation and distance, as the notion of identity and nation. By performing an analytical exercise on this geographical space in the national literature, it is possible to delineate sociological perspectives of the constitution of places such as Os Sertões that in turn, evoke images, texts and debates and differentiated forms of expression of identities and the very notion of nation.
\end{abstract}

Keywords: Sertões; Identities; Nation.

\footnotetext{
${ }^{1}$ Universidade Federal Rural do Rio de Janeiro (UFRRJ), Programa de Pós-Graduação de Ciências Sociais em Desenvolvimento, Agricultura e Sociedade (CPDA), Rio de Janeiro, RJ, Brasil. erikacmalves@gmail.com.

2 Universidade Estadual da Paraíba (UEPB), Graduação em Ciências Sociais, Paraíba, PB, Brasil. diallyson.farias@gmail.com.
} 
Identidade e Nação: o sertão nordestino como retórica social e romanesca.

Revista Ensaios, vol. 13, jul-dez de 2018. ISSN 2175-0564.

Ao consagrar em agosto de 1971 O Romance D’A Pedra do Reino e o Príncipe do Sangue do Vai-e-volta ao escritor Euclides da Cunha, Ariano Vilar Suassuna situa sua obra no cenário da literatura brasileira, mais precisamente na grande gama de escritos que se referenciam como representantes estéticos do que seria o Nordeste brasileiro. Ambiente rústico, pedregoso e seco com retoques de um catolicismo singular, o Nordeste como região, por si gerou determinadas reflexões sobre a identidade nacional com seu maior destaque nos estudos literários sintetizados em Os Sertões. A larga obra euclidiana, publicada em 1902, realiza um passeio sobre o que foi a Guerra de Canudos (1896-1897), ocorrida no interior da Bahia. Trata-se de um texto que apresenta aspectos jornalísticos, somado à outras inflexões de teor sociológico com grande tom determinista sobre aquele dado lugar e os eventos que ali se seguiram. Também representa referências bélicas de uma guerra travada por uma república nascente, até encostar-se à fronteira dos relatos dos destroços humanos de uma Canudos que não se entregou.

Neste artigo, colocaremos em relevo como a escrita euclidiana se ramifica no pensamento estético e literário do escritor paraibano Ariano Suassuna. Anotando que a pretensão do segundo é destacar a imagem de um sertão nordestino fabuloso, em contraponto a um duro realismo social moldado num formato de relatório de guerra apresentado pelo primeiro. Mesmo partindo de pontos distintos, tanto "Os Sertões" como "A Pedra do Reino", trazem à tona a questão inerente de muitos intelectuais, a constituição da identidade nacional, ora esboçada regionalmente, como também etnicamente. Para tanto, e com o propósito de aproximar tais pensamentos e esforço de escrita e leitura, este trabalho colocará no primeiro plano, aspectos que interligam a repercussão de Euclides da Cunha em Suassuna. Este movimento analítico tem como foco delinear que Nordeste é esse que se apresenta nessas obras? Noutro plano, que tipo de homem se esboça em ambas as escritas e quais as influências que podemos apontar para além dos textos e na biografia dos autores? Entendo que ao observar os variados aspectos ali constituídos podemos entender os modos de narração e tipos linguísticos expressados naqueles livros.

Cabe anotar que a construção do conceito de identidade está intrinsecamente relacionada à outra noção, a de nação. Segundo Benedict Anderson (2008, p.32), nação nada mais é do que "uma comunidade política imaginada - e imaginada tanto como limitada quanto soberana por excelência". Trata-se de uma constituição de uma imagem compartilhada por 
Identidade e Nação: o sertão nordestino como retórica social e romanesca.

Revista Ensaios, vol. 13, jul-dez de 2018. ISSN 2175-0564.

uma dada comunidade, que por sua vez, também é considerada por Anderson (op. cit.) como “imaginada, pois membros de uma nação, mesmo da menor delas, nunca conhecerão a maioria de seus conterrâneos, nunca os encontrarão ou até mesmo ouvirão a seu respeito; ainda assim, eles terão em suas mentes a imagem de sua comunhão". É fato que nem todos os membros de uma comunidade de dimensões nacionais estabelecem relações de interação, no entanto há um conjunto de aspectos identitários que evocam um tipo de compartilhamento e reconhecimento mútuo entre seus membros. O autor anota que a origem do conceito de nação fora concebido na Modernidade. Variados processos históricos coincidiram para tanto, no entanto o que nos cabe para esta análise é que para o autor o conceito de nação vai para além dos efeitos institucionais, em outras palavras, nação não significa estaticamente Estado, mas se encontra imbuída de utopias, imagens, ideologias e imaginação.

Acreditamos que este tipo de aparato conceitual pode indicar caminhos para entender que conceitos como identidade, nação e até mesmo de comunidade atravessam variados campos do conhecimento humano, principalmente o da linguagem. É neste tipo de relação que em parte este artigo busca delinear nas obras Os Sertões e a Pedra do Reino. Posto que, em síntese, são obras circunscritas como paisagens sobre uma paisagem, o sertão nordestino. São retratos sobre retratos de um determinado povo, o sertanejo. Mas, nem de longe tratam-se de obras sobre obras, no que concerne aos seus contextos de produção, provocação e intenção de seus autores. Para tanto, torna-se necessário diluir alguns conceitos para entendermos como estas duas obras podem oferecer um campo analítico bastante fértil para as questões que envolvem identidade e nação.

\section{Identidade Nacional e Literatura}

Para Edgar Salvadori de Decca (2002) é uma tarefa difícil definir o que é identidade a partir das narrativas históricas e da literatura. Primeiro, porque nas ciências humanas há variadas definições sobre o tema. Para alguns campos de estudo, a identidade é entendida como uma dimensão da consciência, relacionada aos sistemas de valores em contraposição a personalidade individual ou coletiva. Na psicanálise, por exemplo, a identidade se coloca na esfera do inconsciente, em outras palavras, a questão identitária é significante nos processos oriundos das ações subjetivas. 
Identidade e Nação: o sertão nordestino como retórica social e romanesca.

Revista Ensaios, vol. 13, jul-dez de 2018. ISSN 2175-0564.

O debate sobre as questões identitárias são bastante atuais, posto que há um apelo entre os grupos humanos pela marca da diferença. "Nesse sentido, basta, hoje em dia, a afirmação de um estilo de vida adotado por um grupo de pessoas para que se procure reforçar o princípio da diferença" (DECCA, 2002, p.89). No entanto, numa perspectiva antropológica processualista, as identidades, especialmente as étnicas, processam-se nas relações sociais, ou seja, a identidade é relacional e imperativa. É imperativa, pois os grupos humanos são diversos e as interações sociais se apresentam como arranjos onde estes se aproximam e se distanciam (BARTH, 2000). Este tipo de análise sobre os constructos sociais podem oferecer substratos para a compreensão das conformações identitárias. Uma destas conformações se amplifica nos processos de construção dos Estados Nações. Decca (2002) anota que historicamente a identidade concebida como nacional é uma projeção de uma utopia européia, tal como aferiu o autor mexicano Octavio Paz.

A representação da realidade de uma nação na historiografia e na literatura é marcada por essa utopia. Basta analisarmos o modo como a América é medida pelos europeus, mas especificamente como está se representa na historiografia brasileira, por exemplo. A busca por uma identificação com a utopia pretendida pelo europeu e a construção de uma dada realidade realçou o exótico no que seria o movimento romântico, produto do século XIX. A ideia de identidade nacional não fora produzida pelos nativos (os ameríndios) e muito menos pela população negra trazida da África para utilização de mão-de-obra cativa, posto que estes não eram considerados aptos para se emancipar. A representação romântica da identidade nacional foi idealizada no índio como elo fundante do Brasil. Cabe destacar que tanto a historiografia como a literatura - produzida por brancos - atuavam no sentido de reforçar por meio do contato fundador entre o homem branco com o nativo sul-americano a origem da nação.

Assim, a identidade nacional torna-se assunto de uma classe social branca, que no mínimo deveria ser eurodescendente, a exemplo da obra O Guarani, de José de Alencar. O elemento indígena, moldado no personagem Peri, é glorificado na literatura romântica e na historiografia oitocentista. Na obra de Alencar o cenário da cultura portuguesa encontra-se em estado de ruína, que pode ser conectado com o tempo regressivo presente em Os Sertões. Em contraposição ao índio Peri, o sertanejo presente na obra euclidiana não tem as qualidades de altivez e muito menos controle dos instintos apropriado a um indivíduo civilizado. Antônio 
Identidade e Nação: o sertão nordestino como retórica social e romanesca.

Revista Ensaios, vol. 13, jul-dez de 2018. ISSN 2175-0564.

Conselheiro, líder da comunidade Canudos, representou o Brasil sertanejo, herança da monarquia. "A nova República realizou, assim, o genocídio fundador da nova nacionalidade, ao exilar o pai monarca e massacrar os seus filhos" (DECCA, 2002, p.100).

\begin{abstract}
Nunca um ideal político foi tão carregado de conotações de rejeição ao pai do que aquele construído por homens e mulheres que lutaram pela implantação da República. Modelado pelo ideal republicano francês, o movimento político no Brasil apresentou, como uma de suas mais importantes bandeiras, a forte recusa à tradição colonial e portuguesa, construída ao longo dos séculos de dominação colonial e monárquica [...]. Mas, mais importante ainda do que esse ato, revestido também de forte apelo simbólico, foi a representação literária do Brasil, marcada não só pelo apelo ao exotismo, mas também por um forte realismo, capaz de denunciar o efeito de séculos de colonização. Nesse caso, falamos, é claro, de Euclides da Cunha, que talha o homem brasileiro não mais como um índio majestoso, mas como uma subraça e subproduto de uma desastrosa projeção fantasiosa dos pais portugueses. (DECCA, 2002, p.97).
\end{abstract}

É preciso refletir sobre como se procedeu a implantação do sistema republicano, no contexto brasileiro, Decca (2002) destaca que para os "homens que se projetaram no cenário intelectual e político do final do século XIX, representava, antes de tudo distanciar-se da utopia paterna criada pelos laços familiares portugueses exilando, inclusive, o mais alto representante daquele mandato utópico: o imperador Pedro II” (op. cit. p.96). Se compararmos com o Romance da Pedra do Reino, do Suassuna, os ideais republicanos são vistos como contraponto de um sistema opressor que enxergava o sertão nordestino como fronteira a ser conquistada. É evidente que a figura do Antonio Conselheiro não pode ser reduzida a uma explicação apressada que o enquadre numa perspectiva de movimento messiânico. Por outro lado, embebido de um tipo de realismo proposto por um tipo de choque cultural entre um Brasil oficial e um onde se processa um ideal civilizatório, que se alastra em um território hostil, selvagem e até mesmo medieval, já diagnosticado em Os Sertões, a obra euclidiana é onipresente n'O Romance da Pedra do Reino, tomando até tons dicotômicos como o erudito e o popular, o científico e o tradicional.

Tensão que se apresenta em toda trama como um campo moldado em torno do personagem-narrador que é um sertanejo letrado dado a inspirações míticas e messiânicas devido aos acontecimentos que ocorreram no que o autor nomeia de Serra do Rodeador, local de uma grande tragédia familiar e descrito como o ponto de espera do Dom Sebastião, monarca português que desapareceu na guerra contra os mouros. A monarquia ibérica, ou mesmo o desejo de uma monarquia nos moldes de um sertão bravo e predestinado a receber 
Identidade e Nação: o sertão nordestino como retórica social e romanesca.

Revista Ensaios, vol. 13, jul-dez de 2018. ISSN 2175-0564.

um reinado que unificasse os mais variados principados, representados pelas fazendas, coronéis e vaqueiros. O momento chave da obra é o evento da entrada de um moço num cavalo branco acompanhado de uma cavalgada na cidade de Taperoá, município do Estado da Paraíba. Neste ponto, podemos entender que o termo "brasilidade" ganha aqui os primeiros moldes do seu autor.

Eu concordo que a Cultura brasileira é um episódio da Cultura ocidental, mas não acho que isso indique que não exista uma Cultura brasileira; assim como não deixo de lembrar, a cada instante, que a Cultura ibérica foi, aqui, tão modificada pela negra e pela indígena que, de certa forma, mais do que um episódio da Cultura ocidental, a Cultura brasileira é um ponto de encontro entre ela e as Culturas asiáticas e africanas. (SUASSUNA, 1991, p.128).

A espera de D. Sebastião insere no contexto mais amplo o lugar do Sertão como o ideal de comunidade imaginada esta cavalgada tem tom apocalíptico, pois trazia consigo este cavaleiro que desapareceu após a misteriosa morte do pai, tio do Quaderna (personagemnarrador da obra do Suassuna), o fazendeiro Dom Pedro Sebastião Garcia-Barreto. Tratava-se assim de Sinésio Sebastião, descrito como "o alumiado", montado em seu cavalo branco volta à Taperoá para vingar a morte de seu pai que até então não se tinha desvendado tal crime.

Essa grande "cavalgada" ou "desfilada moura", como caracteriza o próprio autor, ocorre na véspera do Pentecostes de 1935, ou seja, trêsanos antes do tempo de início da narrativa, 1938 (p. 35). Desse modo, Quaderna dá à sua narração uma feição cronística e não apenas épica, como ele mesmo reconhecerá. Esse tempo complicase ainda mais, pois, de saída, o autor adverte para duas singularidades dessa Cavalgada. A primeira delas é que aquele episódio, tal como se as personagens transitassem livremente das narrativas de ficção literária ou do imaginário popular para o vivo palco da história, já havia sido previsto por um brasileiro "alumiado" e "visionário": o poeta Gonçalves Dias (1823-1864), que vivera um século antes. Por "preencher" uma profecia, a cavalgadaleva a narrativa para o tempo sagrado, mítico, em que a cronologiaé relativa; mais do que isso, um tempo além do tempo humano, ou, numa perspectiva tomasiana, um tempo em que tudo é simultâneo (MARTINI \& ROSSATTO, 2014, p.291).

Podemos mais uma vez aproximar a escrita do Suassuna ao realismo euclidiano pela apresentação dos fatos históricos dos movimentos messiânicos que perpassaram o sertão nordestino. Momentos estes que ganham na obra do Ariano, tons literários e fantásticos, como a presunção da figura de D. Sebastião como personagem real e imaginário que atravessa a obra d'Pedra do Reino. Para compreender a travessia dessa imagem é preciso interpretá-la através das suas ramificações no imaginário popular, material utilizado por Suassuna. Cabe anotar que D. Sebastião nasceu em 1554, e foi chamado como "o desejado", este foi filho único do príncipe D. João e do Dona Joana de Áustria, irmã de Filipe II, rei da Espanha, sendo o único herdeiro direto da coroa portuguesa. Quando o príncipe D. João falece antes do 
Identidade e Nação: o sertão nordestino como retórica social e romanesca.

Revista Ensaios, vol. 13, jul-dez de 2018. ISSN 2175-0564.

nascimento de seu filho, D. Sebastião torna-se rei ainda criança, após a morte de seu avô D. João III, entretanto, quem fica com a regência do reinado é sua avó paterna e depois seu tioavô, o cardeal D. Henrique.

O desaparecimento de D. Sebastião na empreitada em Alcácer-Quibir, em 1578, desencadeou uma crise sucessória no Reino de Portugal ${ }^{3}$. Segundo Jacqueline Hermann (2005), o sebastianismo embora seja uma expressão inspirada no desaparecimento do rei submergido no Marrocos, pode ser associado à muitas outras questões, pois "à fé na volta de um rei salvador que viria resgatar o reino português das mãos dos castelhanos e restaurar a honra e a soberania perdida" (op. cit. p. 100), adentrou os mais variados discursos e textos desde finais do século XVI e durante todo o século XVII, período em que alguns autores anotam como o nascimento do sebastianismo propriamente dito.

Fica claro a crença do personagem Quaderna nesta profecia, assim como ficou remetido o sebastianismo aos sertanejos habitantes de Canudos, este tipo de crença popular (MARTINI \& ROSSATTO, 2014). Entretanto, é preciso anotar que aquele ideal utópico proposto inicialmente neste tópico sobre a construção de uma identidade nacional nos contextos literários e históricos, toma aqui uma forma interessante, se atentarmos para a influência do texto euclidiano na obra imaginária do Ariano é possível perceber o embate entre um sertão hostil, selvagem, desconhecido com a "modernidade". Assim, o sertão como espaço a ser civilizado pela era republicana torna-se um lugar atravessado por inúmeras resistências populares, posto que os fatos narrados por Quaderna, por exemplo, remetem ao ano de1935, mais precisamente na véspera de pentecostes ${ }^{4}$. Segundo a historiografia nacional, as primeiras décadas do século XX mais precisamente durante o movimento tenentista e a marcha da coluna Prestes, ambas precedentes da chamada Revolução de 1930, desencadearam movimentos de descontentamentos políticos e sociais por parte de uma parcela da elite política brasileira. Este cenário foi propício para a instauração de um golpe de Estado que levou ao poder Getúlio Vargas em 1930. Tais mudanças no contexto das grandes alianças político-partidárias também se desenrolaram em fatos importantes no nordeste, ocorridos

\footnotetext{
${ }^{3}$ Cinco herdeiros pediram a coroa portuguesa entre os que mais tinham chance estavam, a Catarina de Bragança filha de D. Duarte e, portanto, neta de D Manuel (pai de D. João III), e Felipe II, detentor da coroa de Castela, filho de Carlos V e D. Isabel, filha de D. Manuel. A sentença de 17 de julho de 1580 reconheceu Felipe II como rei, anexando assim Portugal à Espanha.

${ }^{4} \mathrm{O}$ dia de pentecoste faz parte do calendário cristão da Igreja Católica.
} 
Identidade e Nação: o sertão nordestino como retórica social e romanesca.

Revista Ensaios, vol. 13, jul-dez de 2018. ISSN 2175-0564.

estes que perpassam a escrita de Ariano Suassuna como também na trajetória política de sua própria família 5 .

Não muito distante dos fatos políticos e dos feitos de uma República em formação, Euclides da Cunha não passa ileso às questões sociais inerentes a sua época tal como Suassuna. Muito pelo contrário, Os Sertões é um texto em função republicana. Funcionário do Estado, Euclides era o servidor que descreveria os mapas, os eventos, os embates que se travassem no desconhecido sertão. Para tanto, na tentativa de aproximar tais narrativas, uma que caminha em um tempo mítico - O Romance da Pedra do Reino e o Príncipe do Sangue do Vai-e-volta - e outra cheia de realismo e miséria - Os Sertões - anoto algumas questões sobre o cenário, os personagens e os autores.

\section{A terra e seus narradores}

A primeira parte do livro Os Sertões intitulado, A terra, esboça em detalhes as formas agrestes do relevo, do clima, da vegetação e a fauna da região nordestina brasileira. A seca, caracterizada pelas longas estiagens dos ciclos das chuvas, é creditada como fator fatídico pelo qual o sertanejo deve porventura atravessar ao longo de sua vida.

$\mathrm{O}$ autor registra de modo singular que as grandes secas obedecem a um intervalo cabalístico entre nove e doze anos. "Terra ignota" descrita pela agressividade natural que tomou seus solos e pedregulhos. É também revelada como "uma paragem impressionadora" (op. cit. p.11). O sertão descrito é estruturalmente condicionado a passar por grandes remontagens e montagens de uma ordem natural irreversível, tais como os desertos se formaram.

O regímen desértico ali se firmou, então, em flagrante antagonismo com as disposições geográficas: sobre uma escarpa, onde nada recorda as depressões sem escoamento dos desertos clássicos. Acredita-se que a região incipiente ainda está preparando-se para a Vida: o líquen ainda ataca a pedra, fecundando a terra. E lutando tenazmente com o flagelar do clima, uma flora de resistência rara por ali entretece a trama das raízes, obstando, em parte, que as torrentes arrebatem todos os princípios exsolvidos - acumulando-os pouco a pouco na conquista da paragem desolada cujos contornos suaviza - sem impedir, contudo, nos estios longos, as insolações inclementes e as águas selvagens, degradando o solo. (op. cit. p.15).

${ }^{5} \mathrm{O}$ pai de Ariano Suassuna, João Suassuna, foi assassinado na cidade do Rio de Janeiro em meio os embates políticos da década de 1930 . 
Identidade e Nação: o sertão nordestino como retórica social e romanesca.

Revista Ensaios, vol. 13, jul-dez de 2018. ISSN 2175-0564.

As primeiras linhas demonstram ao leitor um lugar semi povoado, formado por geologias de quartzos e camadas de "tabuleiros quem sendo percorridos mostram a acidentação caótica de boqueirões escancelados e brutos" (op.cit. p.17). Toda esta constituição miológica dos interstícios do solo arenoso do sertão baiano acaba por formar uma visão panorâmica do que se revela, ou tende a terminar no Monte Santo, local onde se encruzaria o exército republicano sob o povoado de Canudos, a então vila liderada pelo Antonio Conselheiro. Cenário de combate e resistência. Contudo, é a descrição do alto do morro da Favela que nos permite realizar um paralelo entre escritas e perspectivas linguísticas.

Assim descreve Euclides, como narrador dos fatos:

Galgava o topo da Favela. Volvia em volta o olhar para abranger de um lance o conjunto da terra. E nada mais divisava recordando-lhe os cenários contemplados. Tinha na frente à antítese do que vira. Ali estavam os mesmos acidentes e o mesmo chão, embaixo, fundamente revolto, sob o indumento áspero dos pedregais e caatingas estonadas... Mas a reunião de tantos traços incorretos e duros arregoados divagantes de algares, sulcos de despenhadeiros, socavas de bocainas, criava-lhe perspectiva inteiramente nova. (...) $\mathrm{O}$ arraial, adiante e embaixo, erigia-se no mesmo solo perturbado. Mas vistos daquele ponto, de permeio a distância suavizando-lhes as encostas e aplainando-os - todos os serrotes breves e inúmeros, projetando-se em plano inferior e estendendo-se, uniformes, pelos quadrantes, davam-lhe a ilusão de uma planície ondulante e grande. (op.cit. p.17).

No "Romance da Pedra do Reino; e o príncipe do sangue do vai-e-volta", Suassuna constrói um narrador-personagem, por nome Pedro Dinis Ferreira Quaderna. A obra inicia-se exatamente com este aprisionado na cadeia pública da então vila de Taperoá, sertão da Paraíba.

\begin{abstract}
Daqui de cima, no pavimento superior pela janela gradeada da cadeia onde estou preso vejo os arredores da nossa indomável vila sertaneja. $\mathrm{O}$ sol treme na vista, reluzindo nas pedras mais próximas. Da terra agreste, espinhenta e pedregosa, batida pelo sol esbraseado parece desprender-se um sopro ardente, que tanto pode ser o arquejo de gerações e gerações de cangaceiros, de rudes beatos e profetas, assassinados durante anos e anos entre essas pedras selvagens. (...) Para os lados do poente, longe azulada pela distância, a Serra do Pico, com a enorme Taperoá cuja areia é cheia de cristais despedaçados que faíscam ao sol. Grandes cajueiros, com seus frutos vermelhos e cor de ouro. Para o outro lado, o do nascente, o da estrada de Campina Grande e Estaca-zero, vejo pedaços esparsos e agrestes de tabuleiro, coberto de marmeleiros secos e xiquexiques. Finalmente, para os lados do norte, vejo pedras, lajedos e serrotes, cercando a nova Vila e cercados deles mesmos por favelas, espinhentas e urtigas, (...). (SUASSUNA, p. 31-32).
\end{abstract}

É fato constitutivo das obras que se enquadram e são reconhecidas como epopéias fazer referências a fatos históricos, mitológicos e lendários. Tanto em Os Sertões como n'O Romance da Pedra do Reino encontramos alguns desses elementos. Cabe anotar que o termo 
Identidade e Nação: o sertão nordestino como retórica social e romanesca.

Revista Ensaios, vol. 13, jul-dez de 2018. ISSN 2175-0564.

epopeia, deriva do termo grego épos que significa em síntese, narrativa em versos de fatos grandiosos geralmente centrados na figura de um herói ou de um povo.

Sobre Os Sertões, Alexei Bueno (2012) o considera como uma das três grandes epopeias da língua portuguesa, podendo ser comparada à Ilíada, assim como obras como Os Lusíadas que pode ser comparada à Eneida, e o Grande Sertão Veredas, à Odisseia. Considerada uma obra pré-modernista, o estilo apresentado em Os Sertões é conflituoso, angustiado, tortuoso, o leitor tem acesso ao sofrimento e a luta de um povo sobre si próprio.

Ainda destacamos que o autor faz uso de muitas figuras de linguagem, às vezes omite as conjunções, e as repete reiteradamente em todo texto. Há frequência de mistura de termos de alta erudição tecno-científica, demonstrando o traço de uma obra que se colocava com a pretensão de ser reconhecida como o fato sobre os fatos. A atuação dos neologismos do próprio autor pode ser considerada como marca de um tempo de escrita e inflexão política que o Euclides da Cunha tinha sobre o que deveria ser a república brasileira. Posto que este autor era servidor de um Estado em formação quando de sua ida ao sertão, que até então era tido como um lugar desconhecido para o grande centro político do país da época, o Rio de Janeiro, capital da república. A figura do Conselheiro impunha a recém republica o ajuste de suas causas, como se a cada tentativa de derrubar Bello Monte fosse para provar os ideais republicanos. "O Brasil arcaico e o Brasil moderno estariam presentificados na obra euclidiana de modo crítico e paradoxal, sem que o autor ajuíze qual deles encarnaria a solução cabível para os males do país" (VILLAS BÔAS, 1998, p.158).

As ideias de modernidade e tradição acabam por circunscrever a própria ideia de sobrevivência. Villas Bôas (1998) destaca com veemência que a elite intelectual brasileira, sempre engajada na construção de uma nação e de uma identidade, esboçou de maneira singular as discussões sobre a modernidade. Os eventos das batalhas de Canudos envolveram de forma peculiar estas rodas de debates. O processo civilizatório moderno engendrado pela iniciante república nas terras hostis dos sertões não passou despercebido aos olhos do Euclides da Cunha. "Trata-se de uma história dos vencidos" (op. cit. p.160). Embora, Euclides tenha se libertado de relatar as (des)continuidades do passado sertanejo, este faz um apelo ao descrever o "evento extraordinário" para os "corações e mentes", do que para os arranjos legais republicanos. 
Identidade e Nação: o sertão nordestino como retórica social e romanesca.

Revista Ensaios, vol. 13, jul-dez de 2018. ISSN 2175-0564.

Devo destacar que a construção de um Ethos Iluminista que se colocava à intelectualidade brasileira naquele dado momento é um importante aspecto no que se refere a algumas posturas do Cunha - para dentro e fora da sua obra. A autora destaca que não é possível perceber a intenção de superar ou mesmo de preservar o tempo passado vivenciado pelo "sertanejo". Cabe destacar que o tempo passado aqui, experimentado pelo sertanejo, é o passado português. Em outras palavras, este passado é o elo integrador da cultura dos sertões.

$\mathrm{Na}$ obra euclidiana a construção da identidade presente no interior é o de uma coletividade mestiça, mais branca e indígena do que negra. Coletividade que também era valente e bronca. O caráter de epopeia apresentado em Os Sertões não se configura na descrição de um herói, mas sim de um povo, e no caso, mesmo vencido é moldado no perdedor, o sertanejo.

O personagem de Pedro Dinis Ferreira Quaderna, no Romance da Pedra Reino, narra fatos grandiosos de sua gente e de si mesmo, tons característicos de uma pretensa epopeia que nos termos do Suassuna é "uma espécie de Sertaneidade, Nordestíade, ou Brasiléia" (2006, p.241). Em busca da honra e soberania dos seus antepassados, Quaderna se considera também, tal como o sertanejo descrito pelo Euclides da Cunha, mais branco - com ascendência portuguesa - e indígena do que negra.

Ao utilizar o termo "malhado" ao mestiço, o narrador-personagem busca em toda obra relatar os acontecimentos que levaram à morte de seu tio e padrinho Dom Pedro Sebastião Garcia-Barreto e com isso apresentar sua importância literária à Academia Brasileira de Letras, como "gênio da raça brasileira" que é malhada tal como ele é. Quaderna considera que o sertão é terra de uma gente nobre, tal como os nobres europeus - mais especificamente a região ibérica. O romance é preenchido por referências de uma busca e exaltação de um passado histórico e imaginário. Em outras palavras e respectivamente o que se encontra na então obra pode ser caracterizado pelo que seria a Idade Média na península Ibérica e de um suposto sistema de feudos e principados presentes no sertão nordestino. Assim, a épica se reapresenta na montagem de um sertão fabuloso, fantástico e rústico.

Este tipo de linguagem deve-se a própria biografia do autor, posto que Ariano Suassuna é fundador de um movimento artístico conhecido como Movimento Armorial. Lançado em 18 de outubro de 1970 em Recife, capital do Pernambuco, o Movimento Armorial teve forte 
Identidade e Nação: o sertão nordestino como retórica social e romanesca.

Revista Ensaios, vol. 13, jul-dez de 2018. ISSN 2175-0564.

intersecção e atuação nos centros acadêmicos. Tinha como objetivo fundir a arte erudita com a arte da cultura popular nordestina. Segundo seu idealizador, o termo "armorial" referia-se ao conjunto de insígnias, brasões, estandartes e bandeiras de um povo. Desse modo, armorial seria o nome apropriado para o desejo de ligação com essas heráldicas raízes culturais brasileiras. Neste sentido, ao destacar alguns elementos desta escolha de narrativa do Ariano Suassuana podemos realizar inflexões sobre as escolhas e os caminhos percorridos pelo Euclides da Cunha.

\section{Entre Autores e o Molde da Escrita: Algumas considerações finais}

Euclides da Cunha (1866-1909) ficou órfão de mãe aos três anos de idade. Aos 19 anos ingressou na Escola Politécnica, ali cursou um ano de Engenharia Civil e depois se matriculou na Escola Militar da Praia Vermelha. Escrevia para a revista escolar "A Família Acadêmica". Fora expulso da Academia por afronta ao Ministro da Guerra do Império. Muda-se para São Paulo e publica uma coletânea de artigos que panfletaram os ideais republicanos.

Depois de proclamada a República, Euclides da Cunha retorna para o Rio de Janeiro, sua terra natal. Entre 1890 e 1892, volta ao Exército, formando-se em Engenharia Militar pela Escola Superior de Guerra ${ }^{6}$. Afasta-se do exército em 1896, e trabalha como superintende de obras em São Paulo. Neste período volta a contribuir para o jornal o Estado de São Paulo. Em agosto do ano seguinte, é convidado pelo jornalista Júlio Mesquita para retratar as operações militares na então Guerra de Canudos. Suas mensagens eram transmitidas por telégrafo para o jornal paulista. Ao regressar do sertão baiano, palco dos confrontos, Cunha vai para São José do Rio Pardo, em São Paulo, para supervisionar uma construção de uma ponte. Naquele cenário escreve o livro que o consagrou na literatura nacional. Os Sertões é publicado como antes mencionado em 1902, cinco anos depois do término do conflito.

Ao contrário de Euclides da Cunha que foi levado para uma terra distante, Ariano Vilar Suassuna (1927-2014) retrata as imagens que lhe são familiares. Este nasceu na cidade de Nossa Senhora das Neves, atual João Pessoa, da capital da Paraíba. Filho de Rita de Cássia Vilar e João Suassuna, ex-governador daquele Estado. Os primeiros anos de sua vida, Ariano

\footnotetext{
${ }^{6}$ Euclides da Cunha bacharelou-se também no ensino militar, em Matemática e Ciências Físicas e Naturais. Em 1893, trabalha na Estrada de Ferro Central do Brasil em São Paulo, justamente na época da Revolta Armada, levante que pretendia derrubar o governo de Floriano Peixoto.
} 
Identidade e Nação: o sertão nordestino como retórica social e romanesca.

Revista Ensaios, vol. 13, jul-dez de 2018. ISSN 2175-0564.

viveu na fazenda Acahuam, sertão paraibano. Na Revolução de 1930, por embates políticos que fervilham no país, o seu pai foi assassinado. Este fato levou toda sua família a morar em Taperoá, no interior do Estado, terra dos parentes de sua mãe. Ali residiu de 1933 até 1937 e iniciou seus estudos. Foi em Taperoá que o próprio autor relata de seu primeiro contato com a cultura popular, posto que foi na feira local, onde assistiu uma apresentação de mamulengos e desafios de viola.

Em Recife, capital de Pernambuco, Ariano ingressa em importantes escolas com o Ginásio Pernambucano. Em 1946 inicia seus estudos na Faculdade de Direito, ali funda o Teatro do Estudante Pernambucano ${ }^{7}$. Ao concluir o curso de Direito, em 1950, passa a se dedicar a advocacia e ao teatro. Após seis anos inicia sua carreira na licenciatura, dando aula de Estética na Universidade Federal de Pernambuco. Ao criar o Movimento Armorial na década de 1970 do século XX, Ariano reinventa o sertão nordestino retratado pelo realismo de Euclides da Cunha.

O Brasil real, mítico, quase que completamente medieval, também mágico e maravilhoso que a literatura de Ariano e o Movimento Armorial vão buscar na obra de Euclides. Trata-se de um ato de restituir, por meio da estética, a sua unidade. Desse espaço geográfico eles não recolhem o determinismo, o positivismo e o evolucionismo social de "Os Sertões", mas, as formas fixas da "sextilha", a música de viola, rabeca, zabumba, pífano, o canto do aboio como também das xilogravuras dos folhetos de cordel; a heráldica popular manifestada nos ferros de marcar bois e nas bandeiras das cavalhadas; a alegoria da onça, dos dragões, dos "cachorros endemoniados", dos ex-votos, dos santos, profetas, mitos e personagens nordestinos.

Assim, o que em Euclides era uma região que encerrava todas as condições para gerar monomanias raciocinantes ou instintivas - a chamada loucura moral - Suassuna, como um crítico da modernidade, vai dedilhar pela via do universo simbólico, a matéria-prima para se forjar uma arte que se queira, dentro da sua concepção, verdadeiramente brasileira.

Para Euclides, o sertanejo — antítese do gaúcho — "é desgracioso, desengonçado, torto", sendo "impossível idear-se cavaleiro mais chucro e deselegante", apesar do seu aspecto "recordar, vagamente, à primeira vista, o de guerreiro antigo exausto da refrega. As

\footnotetext{
${ }^{7}$ Em 1947 através das atividades no Teatro do Estudante de Pernambuco, escreve sua primeira peça "Uma
} mulher vestida de sol". 
Identidade e Nação: o sertão nordestino como retórica social e romanesca.

Revista Ensaios, vol. 13, jul-dez de 2018. ISSN 2175-0564.

vestes são uma armadura”. Ariano, segue por outra perspectiva, tira esse cavaleiro da sua vida simplória para o centro de uma Cavalgada, denominada por ele de "Armorial Cavalaria Sertaneja", e o cobre de alegorias e enfeites. A singela "armadura" de couro do sertanejo transforma-se em "armadura negra e escarlate, de placas de aço, incrustada de esmaltes e brasões, parecendo, o todo, a carapaça dura, calcária, espinhosa e violeta-escarlate de um crustáceo gigantesco encravado num penhasco".

Ao relatar os costumes religiosos como um tipo de "caráter variável da religiosidade sertaneja", Euclides denota que as condições do clima e da terra no Sertão dão ao sertanejo a "consciência da fraqueza para as debelar", daí ele "apelar constantemente para o maravilhoso, esta condição inferior de pupilo estúpido da divindade”. Euclides exemplifica esse tipo de pensamento à promessa que foi aventada no episódio da "Pedra do Reino", a de que o sangue derramado das crianças sobre a pedra estabeleceria o "advento do reino encantado do rei D. Sebastião". Por outro lado em Ariano, o fanatismo e os recursos do maravilhoso denunciados por Euclides transformam-se na fala de Quaderna: a de "que o exército d'El-Rei Dom Sebastião viria era para destruir os poderosos", que os cachorros degolados junto com as crianças iriam ressuscitar em forma de dragões, "para devorar todos os proprietários, repartindo-se então as terras dos finados com os pobres”. Em síntese, o que era fanatismo para Euclides da Cunha, para Ariano é "'um como que pensamento socialista".

Euclides enxergava o sertão como a última fronteira do medievo a ser debelada pela força da civilização. Ariano, em contraposição, e superando esta visão do cientificismo de Euclides, encontra no sertão, um Brasil profundo que pode servir de fonte de inspiração para uma arte genuinamente brasileira. No dizer do personagem Euclydes Villar, em A Pedra do Reino, a literatura se alimenta da "invenção fantasiosa", só por meio de um pouco de "mentira" é que os poetas podem ver "joias, ouro, pratas e pedras preciosas em todo canto."

Acredito que como os regionalistas da primeira metade do século XX, Ariano se inspirou nos escritos do Euclides da Cunha. Configurar um outro sertão, para além de suas desigualdades sociais e enxergando em suas singularidades, fontes inspiradoras para conformar a Arte - seja na literatura, nas pinturas e profundamente num tipo de estética. Aquele sertanejo descrito como um Hércules com junção com Quasímodo n’Os Sertões transfigura-se em um Cavaleiro medieval que se arma contra os efeitos da modernidade, modernidade esta inspirada nos moldes republicanos que em solo brasileiro tomou formas 
Identidade e Nação: o sertão nordestino como retórica social e romanesca.

Revista Ensaios, vol. 13, jul-dez de 2018. ISSN 2175-0564.

bastante brutais para com os "descamisados". O que era penhor para Euclides, torna-se material para Suassuna.

\section{Referências}

ALENCAR, J. de. O Guarani. Rio de Janeiro: José Olympio, 1991.

ANDERSON, B. Comunidades imaginadas: reflexões sobre a origem e difusão do nacionalismo. São Paulo: Companhia das Letras, 2008.

BARTH, F. O guru, o iniciador e outras variações antropológicas. Rio de Janeiro: Contra Capa Livraria, 2000.

BUENO, Alexei. "Ribeiro, Rego, Rosa e Rocha: Afinidades Eletivas" em Machado, Euclides \& Outros monstros. São Paulo: B4 Editores, 2012.

CUNHA, E. da. Os Sertões. Rio de Janeiro: Francisco Alves, 1995.

DECCA, E. S. Tal pai, qual filho?:narrativas histórico-literárias da identidade nacional. Proj. História. São Paulo (24), jun. 2002.

HERMANN, Jacqueline. Antônio Vieira e o Sebastianismo: messianismo régio e transfiguração barroca. In: COSTIGAN, L. H. (Org.).Diálogos da conversão. Campinas: Ed. da Unicamp, 2005.

MARTINI, M. de. ROSSATTO, N. D. Alegoria e utopia em "O Romance d'A Pedra do Reino", de Ariano Suassuna. Letras, Santa Maria, v. 24, n. 49, p. 285-311, jul./dez. 2014.

SUASSUNA. A. V. O romance da pedra do reino e o príncipe do sangue do vai-e-volta. São Paulo: Editora Olympio, 2006.

SUASSUnA, A. V. Uma Teoria da Arte Rupestre. In: Anais I Simp. Pré-Hist. Nordeste. Clio, 4, 1991.

VENTURA SANTOS, R. Aobra de Euclides da Cunha e os debates sobre mestiçagem no Brasil no início do século xx: Os sertões e a medicina-antropologia do Museu Nacional. Hist. cienc. saude-Manguinhos.v.5, Rio de Janeiro jul. 1998.

VILLA BÔAS, G. Iluminista e Romântico: o tempo passado em Os Sertões de Euclides da Cunha. Hist. cienc. saude-Manguinhos.v.5, Rio de Janeiro jul. 1998. 